\title{
Numerical Analysis of ACSR Conductor-Clamp Systems Undergoing Wind-Induced Cyclic Loads
}

\author{
Sébastien Lalonde, Raynald Guilbault and Sébastien Langlois
}

\begin{abstract}
Submitted to wind induced vibrations, overhead conductors are vulnerable to fatigue damage, especially at restraining fixtures such as the suspension clamp. This paper proposes an efficient finite element modeling approach providing a full 3D representation of both the conductor and suspension clamp. Validation based on experimental data shows the precision of the approach. An in-depth model response analysis also demonstrates its ability to describe inter-wire and conductor-clamp contact interactions. Finally, a study of conductor stress distributions reveals that in critical regions, conductor wires mostly sustain alternating bending loads.
\end{abstract}

Index Terms-Overhead conductors, Suspension clamps, Aeolian vibrations, Fretting fatigue, 3D Finite element modeling

\section{INTRODUCTION}

$\mathrm{W}$ ind-induced vibrations are well known to cause fatigue problems in overhead conductors. Producing alternating bending deflections near restraining fixtures, these vibrations have detrimental effects in the vicinity of suspension clamps [1]. At that position, conductors are also subjected to significant static loads combining an axial tension $(T)$, a sag bending force described by a deflection $\left(\beta_{0}\right)$, and a clamping force $\left(F_{C}\right)$ exerted by the clamp (Fig. 1a) [2]. This load combination promotes conductor fretting fatigue and wear at inter-wire contact points [3] that could lead to premature strand failure.

Given the critical importance of maintaining the structural integrity of electrical transmission networks, it is essential to quantify and understand the conductor load conditions, to be able to predict and prevent fatigue failures. Incidentally, this paper proposes a 3D finite element (FE) modeling approach for the analysis of conductor-clamp systems considering the effect of the aforementioned static and dynamic loadings. The developed FE strategy aims at providing detailed descriptions of the mechanical loads in the wires. These loads are crucial for the assessment of conductor fatigue damage.

S. Lalonde was with the Department of Civil Engineering at Université de Sherbrooke, Sherbrooke, QC J1K 2R1 Canada. He is now with Helix/Preformed Line Products, Lachine, QC, H8T 3J9 Canada (e-mail: slalonde@helix-uni.ca).

R. Guilbault is with the Department of Mechanical Engineering at École de technologie supérieure, Montreal, QC H3C 1K3 Canada (e-mail: Raynald.Guilbault@etsmtl.ca)

S. Langlois is with the Department of Civil Engineering at Université de Sherbrooke, Sherbrooke, QC J1K 2R1 Canada. (e-mail: Sebastien.Langlois@Usherbrooke.ca).

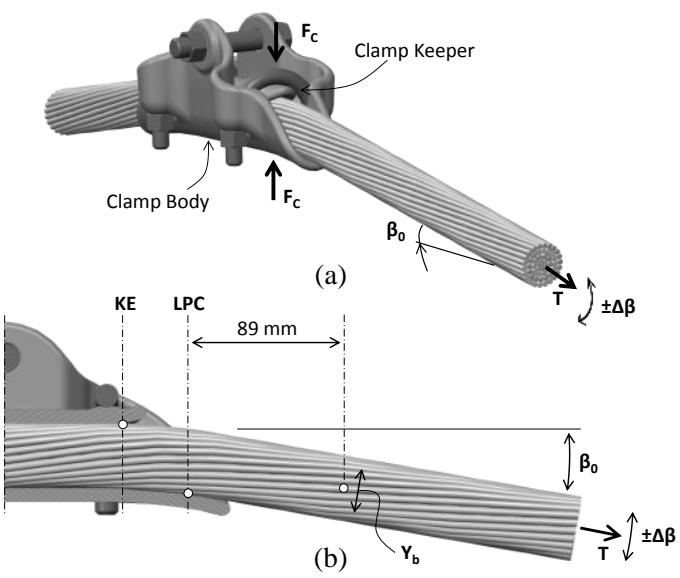

Fig. 1. (a) Usual loading conditions at the suspension clamp and (b) Schematization of $Y_{b}$ measurement at a suspension clamp

The conductor load severity is conventionally evaluated from the bending deflection amplitude $\left(Y_{b}\right)$. This indirect descriptor is measured at $89 \mathrm{~mm}$ from the Last Point of Contact $(L P C)$ between the strand and the suspension clamp (Fig. 1b) [4]. When associated with the well-known Poffenberger-Swart (P-S) formula (1), $Y_{b}$ provides an estimated stress amplitude $\left(\sigma_{a}\right)$ of the outermost fiber of the conductor at the $L P C$ position [5].

$\sigma_{a}=\frac{d_{c} E_{a}\left(\frac{T}{4 E I}\right)}{e^{-\sqrt{T / E I Z}}-1+\sqrt{T / E I Z}} Y_{b}$

In (1), $T$ represents the axial tension, $d_{c}$ is the diameter of the conductor wires, $E_{a}$ stands for the Young modulus of the aluminum wires and $E I$ represents the bending stiffness of the strand. Parameter $\mathrm{z}$ is the axial position set at $89 \mathrm{~mm}$.

In the P-S formulation, the conductor is considered as a cantilever beam, with its fixed end representing the $L P C$. In other words, the formulation considers no clamping or other fixture effect. Moreover, each wire is assumed to act independently without any friction influence. This frictionless condition leads to a theoretical minimal bending stiffness $\left(E I_{\text {min }}\right)$. This simplification also neglects complex wire contact interactions. Nevertheless, this idealized stress has been shown to correlate surprisingly well with experimental fatigue data. It therefore constitutes a useful fatigue indicator relating the vibration amplitude $\left(Y_{b}\right)$ to experimental conductor life measurements [6].

Clearly, the standardized approach does not directly address the essence of the problem. As a result, refining the conductor 
fatigue analysis or improving the problem interpretation become very difficult. Moreover, since the mechanisms relating the external loads to fatigue damage are not well defined, any optimization of suspension clamp designs is therefore challenging.

Only few published studies have integrated the influence of the suspension clamp geometry into the analysis of conductor strain and fatigue responses. For example, experimental tests investigating the effect of the clamp curvature [2] showed that an increase of the longitudinal radius reduces the static and dynamic strains, and leads to longer service lives. Cardou et al. [7] studied the contact conditions at the conductor-clamp interface using an instrumented suspension clamp. They reported maximum loads near $L P C$. Lévesque et al. [8] analyzed isolated wire-clamp contacts from experimental strain measurements and presented a detailed numerical description of the local stress conditions associated with fretting fatigue.

Although these studies provided essential information on fatigue mechanisms, a clear quantitative relation or modeling tool is still not currently available to describe with sufficient precision the conductor solicitations resulting from given clamp-load configurations. Thus, a general analysis method enabling a direct quantification of local loads associated with parameters such as stranded properties, inter-wire contacts, clamp geometry and load configuration is still to be developed [9]. The conductor-clamp model proposed in this paper is intended to provide a solution to that end.

The proposed approach is based on a FE modeling strategy developed by the authors in [10] for multilayered wire strands, and is applied herein to the analysis of conductor windinduced loads. Section II of the paper provides a detailed description of the FE model, while section III validates the proposed approach via a comparison of the obtained numerical results to published strain measurements. The model response is then exploited in section IV to analyze the conductor internal efforts in the clamped area, where fretting fatigue problems are expected to be prominent.

\section{FINITE ELEMENT MODEL}

The proposed FE modeling approach is developed within the commercial software, Ansys ${ }^{\circledR}$ 15.0. The following details the formulation and describes the conductor-clamp configurations analyzed in this work.

\section{A. Conductor-Clamp General Model Configuration}

Although the proposed approach is general and suitable for any conductor-clamp configuration, the validation of the procedure considers the fatigue tests detailed in [11]. The analysis thus focuses on two conductor-clamp systems composed of two ACSR conductor types: a Bersfort and a Drake. Table I present the stranding properties (reproduced from [12]) of these conductors with parameters $n_{i}, d_{i}, E_{i}$ and $\alpha_{i}$ referring to the layer $i$ wire number, the wire diameter, the Young modulus and the lay angle, respectively.

Fig. 2 illustrates the parameters defining the conductorclamp geometry. The parameters values are given in Table II. Reference [13] provides some additional geometric information. The transverse clamp curvature profile (defined by $\mathrm{R}_{\mathrm{C}, 2}$ ) is assumed to comply with the external diameter of the conductor.

TABLE I

ACSR STRANDING PROPERTIES

\begin{tabular}{ccccccccc}
\hline \hline \multirow{2}{*}{ Layer } & \multicolumn{9}{c}{ Drake } & \multicolumn{5}{c}{ Bersfort } \\
\cline { 2 - 9 } & $\mathrm{n}_{\mathrm{i}}$ & $\mathrm{d}_{\mathrm{i}}(\mathrm{mm})$ & $\mathrm{E}_{\mathrm{i}}(\mathrm{GPa})$ & $\alpha_{\mathrm{i}}\left(^{0}\right)$ & $\mathrm{n}_{\mathrm{i}}$ & $\mathrm{d}_{\mathrm{i}}(\mathrm{mm})$ & $\mathrm{E}_{\mathrm{i}}(\mathrm{GPa})$ & $\alpha_{\mathrm{i}}\left({ }^{0}\right)$ \\
\hline Core & 1 & 3.45 & 207 & - & 1 & 3.32 & 207 & - \\
1 & 6 & 3.45 & 207 & 5.8 & 6 & 3.32 & 207 & 6.2 \\
2 & 10 & 4.44 & 69 & 10.7 & 10 & 4.27 & 69 & 9.7 \\
3 & 16 & 4.44 & 69 & 12.9 & 16 & 4.27 & 69 & 10.7 \\
4 & - & - & - & - & 22 & 4.27 & 69 & 11.7 \\
\hline \hline
\end{tabular}

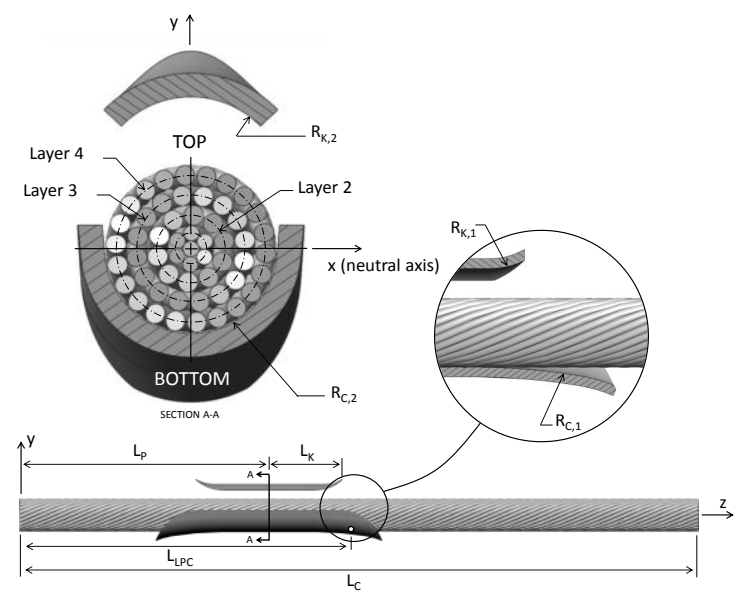

Fig. 2. Schematic representation of the conductor-clamp configuration

The modeled conductor segment length $\left(L_{C}\right)$ and longitudinal positioning $\left(L_{P}\right)$ are selected to minimize the effects of the boundary conditions generated at the exit of the clamp, as well as the FE model computational cost. The length $L_{L P C}$ identifies the actual $L P C$ locations identified in [11]. For comparison purposes, the following presentation of the results refers to these reference locations. However, in some cases, the $L P C$ numerical predictions are slightly different.

TABLE II

GEOMETRIC PARAMETERS OF CONDUCTOR-CLAMP SYSTEMS

\begin{tabular}{lcccccccc}
\hline \hline Conductor & $\begin{array}{c}\mathrm{L}_{\mathrm{C}} \\
(\mathrm{mm})\end{array}$ & $\begin{array}{c}\mathrm{L}_{\mathrm{P}} \\
(\mathrm{mm})\end{array}$ & $\begin{array}{c}\mathrm{L}_{\mathrm{LPC}} \\
(\mathrm{mm})\end{array}$ & $\begin{array}{c}\mathrm{L}_{\mathrm{K}} \\
(\mathrm{mm})\end{array}$ & $\begin{array}{c}\mathrm{R}_{\mathrm{C}, 1} \\
(\mathrm{~mm})\end{array}$ & $\begin{array}{c}\mathrm{R}_{\mathrm{C}, 2} \\
(\mathrm{~mm})\end{array}$ & $\begin{array}{c}\mathrm{R}_{\mathrm{K}, 1} \\
(\mathrm{~mm})\end{array}$ & $\begin{array}{c}\mathrm{R}_{\mathrm{K}, 2} \\
(\mathrm{~mm})\end{array}$ \\
\hline Drake & 1600 & 600 & 687 & 89 & 178.6 & 14.1 & 10.7 & 14.1 \\
Bersfort & 1600 & 600 & 684.75 & 66.75 & 330 & 17.8 & 40 & 18 \\
\hline \hline
\end{tabular}

\section{B. Conductor FE Model}

The numerical modeling approach validated in [10] ensures a full 3D processing of the conductor geometry, where each wire is modeled with quadratic beam elements (BEAM189 in Ansys $^{\circledR}$ ) defined by their helix centerline curves (Fig. 3). The resulting reduced mesh size leads to more efficient models than volumetric representations made of solid elements [14]. A mesh size sensitivity analysis (not included here) showed that a beam element length of $10 \mathrm{~mm}$ provides precise solution convergence and optimal CPU times.

A 3D line-to-line algorithm using master-slave contact element pairs mapped onto the beam elements handles all contact interactions between wires (radial and lateral contacts) (Fig. 3). Ansys ${ }^{\circledR}$ CONTA176 and TARGE170 elements correspond to slave and master elements, respectively. The penalty method integrated into the solution to deal with the 
contact forces considers the normal and tangential stiffness values to prevent both penetration and elastic slip. This option also ensures good convergence rates.

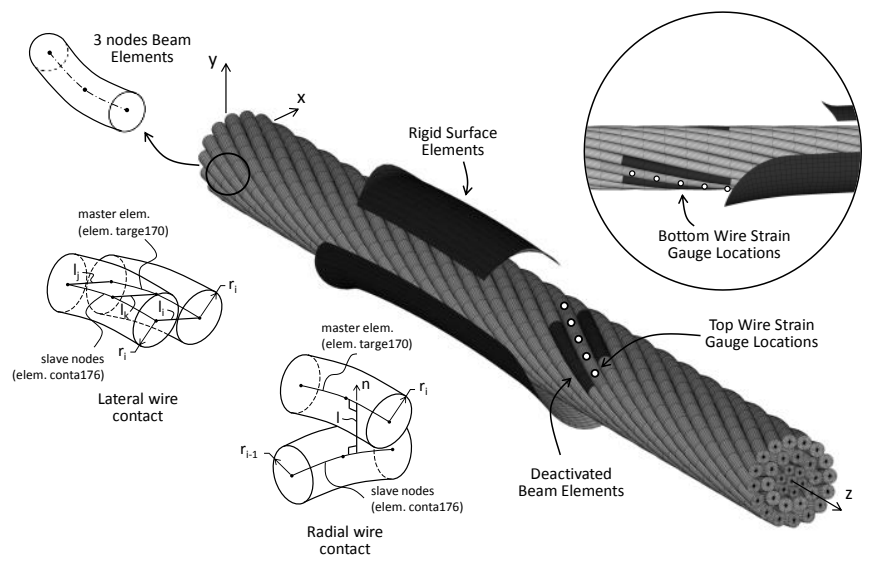

Fig. 3. Conductor-Suspension clamp finite element model (ACSR Drake configuration shown)

Frictional effects are taken into account at each contact point-line via the Coulomb law considering an adhesion coefficient of friction $\left(\mu_{a}\right)$. For aluminum-aluminum and aluminum-steel contacts, $\mu_{a}$ is set to 0.5 , whereas a value of 0.3 is used for steel-steel contacts.

When applied to the ACSR Bersfort configuration of Table II, this modeling approach leads to a FE model of 9,240 beam elements, 18,535 nodes and 5,252 contact points/lines pairs.

\section{Suspension Clamp FE Model}

The clamp geometry is considered as a rigid surface, and is modeled with 3D quadratic surface elements ( 8 nodes). The clamp body and keeper geometries (Fig. 3) are represented by surface elements with a $2.5 \mathrm{~mm}$ average length. The contact lines at the conductor-clamp interface are handled with a 3D line-to-surface algorithm, where the slave nodes (CONTA177 elements) are mapped onto the wires beam elements, and the master elements (TARGE170) are generated onto the rigid surface elements (Fig. 4). The "rigid surface" approach provides computational efficiency, and since the analysis concentrates on the conductor response, we consider that this simple clamp model should have no noticeable effect on the final precision.

As before with the line-to-line solution, the penalty approach ensures the same normal and tangential stiffness representation. The aluminum-aluminum friction coefficient $\left(\mu_{a}\right)$ also remains the same.

The clamp mesh required for the ACSR Bersfort case leads to a mesh size of 4,295 surface elements and 13,329 nodes.

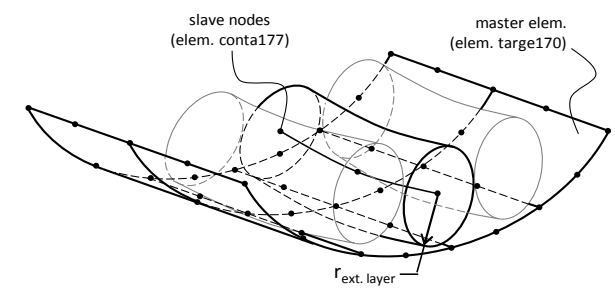

Fig. 4. 3D Line-to-surface contact elements for wire to clamp contacts

\section{General Boundary Conditions and Node Coupling}

The nodes of the cross-section of each conductor extremity are fully coupled (all 6 DOF) with the central node located on the core. Therefore, the coupled nodes act as a rigid surface allowing external loads to be applied at the core node only.

Since the clamp surfaces are modeled as rigid bodies, their DOF are controlled via a pilot node on each of them. The clamp body is fully constrained in all directions and rotations, while only the vertical displacement ( $y$ direction) is allowed for the keeper.

\section{E. Loads Description and Application Sequence}

Since Lévesque et al.'s experimental works [11] were conducted on a $7 \mathrm{~m}$ resonant test bench, the numerical simulation requires a multiple-load procedure, with the loads applied in an incremental quasi-static mode following the 10load step sequence illustrated in Fig. 5.

Load step 1 applies an initial tension $T_{0}$ to the conductor passive end and generates a vertical displacement up to a static deflection angle $\beta_{P}$. The second conductor extremity remains fixed. During Load step 2, the passive extremity is blocked in place; a displacement condition replaces the force condition, while on the active side, the conductor tension $T_{0}$ applied at a static sag angle $\beta_{0}$ replaces the displacement restrain. During Load steps 3 and 4, the axial tension is raised from $T_{0}$ to $T$. In fact, to follow the testing procedure of [11], during Load step 3, $T$ is first brought to $30 \%$ of the conductor RTS, and thereafter, is reduced to the testing condition with $T=$ $25 \%$ of RTS (during Load step 4).

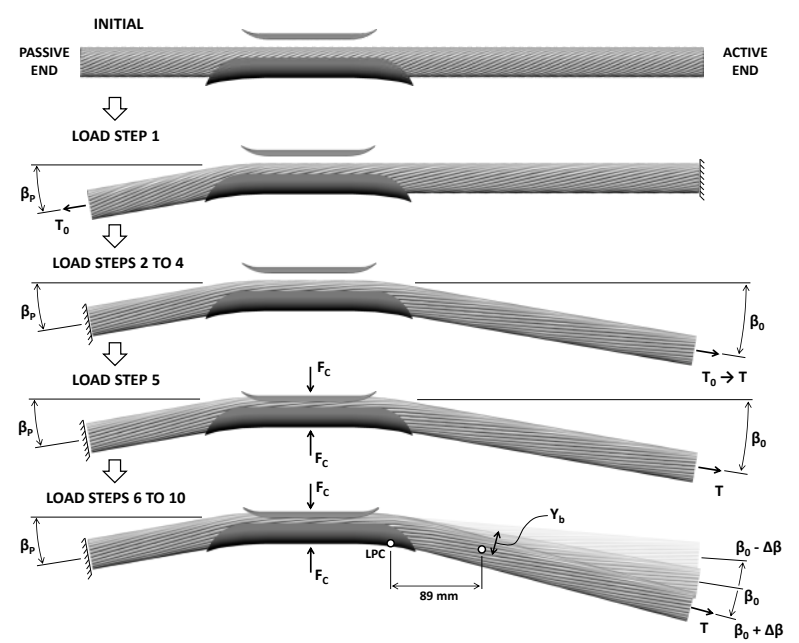

Fig. 5. FE analysis load application sequence

Load step 5 introduces the clamping effect with a vertical force $\left(F_{C}\right)$ applied to the pilot node of the keeper. $F_{C}$ is calculated with equation (2) [15]. Equation (2) relates the applied bolting torque $\left(T_{C}\right)$ to the clamping force. Ref. [11] reported a torque $T_{C}$ of $47.5 \mathrm{Nm}$.

$F_{c}=n\left(\frac{T_{c}}{K \cdot d_{b}}\right)$

In equation (2), $n$ is the number of torqued bolts (here, $n=4$ ), $d_{b}$ is the nominal bolts diameter (here $12.7 \mathrm{~mm}$ ). Finally, $K$ 
represents the thread friction and is considered here to be equal to 0.2 (as suggested in [15] for galvanized threads). Once the application of $F_{C}$ is completed, the keeper is locked in place by substituting the vertical force with the corresponding displacement in the $y$ direction.

Load steps 6 to 10 are associated with the dynamic loadings; the application angle of $T$ is varied by $\pm \Delta \beta$ from the static position $\beta_{0}$. The value of $\Delta \beta$ is iteratively calculated to produce the deflection $Y_{b}$ established in [11]. $Y_{b}$ is measured at $89 \mathrm{~mm}$ from the $L P C$ position. Evaluation tests indicated that two load cycles were sufficient to reach a stabilized hysteresis conductor bending behavior [10].

Table III presents the load parameters value for the ACSR Drake and Bersfort configurations.

TABLE III

LOADING PARAMETERS OF MODELED CONDUCTOR-CLAMP

\begin{tabular}{|c|c|c|c|c|c|c|c|}
\hline Conductor & $\begin{array}{c}\mathrm{T}_{0} \\
(\mathrm{kN})\end{array}$ & $\begin{array}{c}\mathrm{T}_{30 \% \mathrm{RTS}} \\
(\mathrm{kN})\end{array}$ & $\begin{array}{c}\mathrm{T}_{25 \% \text { RTS }} \\
(\mathrm{kN})\end{array}$ & $\mathrm{F}_{\mathrm{C}}(\mathrm{kN})$ & $\beta_{\mathrm{P}}\left({ }^{\circ}\right)$ & $\beta_{0}\left({ }^{\circ}\right)$ & $\Delta \beta\left(^{\circ}\right)$ \\
\hline Dral & 7.82 & 45 & 32 & 74.8 & 4.3 & 7 & \\
\hline Bersfort & 1.85 & 54 & 45 & 74.8 & 4.3 & 6.2 & \\
\hline
\end{tabular}

* Iteratively defined for each $Y_{b}$

All simulations were performed on a desktop computer equipped with a $2.9 \mathrm{GHz}$ quad-core CPU and $12 \mathrm{~GB}$ RAM. The average solution time was 14 to 18 hours. Compared to other 3D multilayered strand models based on volumetric representations, such as those described in Ref. [14] for similar model precision levels, the proposed approach appears to be cost-effective. Because of this important advantage, the proposed modeling strategy is not limited to the usual length size ( $\approx 1$ pitch length or less) or restricted to the load type associated with other 3D modeling procedures, which only consider axial loads.

Real field conditions combine various aspects such as wind and temperature load variations or clamp rotations which are not considered during experimental testing, and therefore are not investigated herein. In reality, while the complexity of field loadings is very difficult to replicate experimentally [1], it poses no serious difficulty to the numerical avenue. Therefore, the modelling efficiency of the approach proposed in this study should favor deeper analysis in a near future.

\section{MODEL VALIDATION}

This section compares the proposed conductor-clamp modeling approach to experimental conductor strain measurements published in Ref. [11].

\section{A. ACSR Drake Case Study}

In their work, Lévesque et al. [11] measured the strains on TOP and BOTTOM wires of the external layer of ACSR conductors (Fig. 3). At each measurement location, three strains, $\varepsilon_{C}, \varepsilon_{L}$, and $\varepsilon_{R}$, were monitored with the arrangement showed in Fig. 6(a). Here, the indices $C, L$ and $R$ stand for Center, Left and Right, respectively. Sections of the adjacent wires were removed to allow the installation of the strain gages $\varepsilon_{L}$ and $\varepsilon_{R}$. Therefore, to account for the wires removed in the FE model, affected beam elements are simply "deactivated" by reducing their stiffness down to $5 \%$ of their original value. To illustrate the model capacities, Fig. 6(b) shows the ACSR Drake deformation and associated Von Mises stress distributions established during Load step $10\left(\beta_{0}\right.$ $+\Delta \beta$ ) and a corresponding $Y_{b}$ of $0.90 \mathrm{~mm}$.

Since the reference strain measurements were recorded relative to the initial tension $T_{0}$, the numerical strain values calculated at $\mathrm{T}_{0}\left(\varepsilon_{T 0}\right)$ are also subtracted from the total strain $\left(\varepsilon_{t o t}\right)(3)$ :

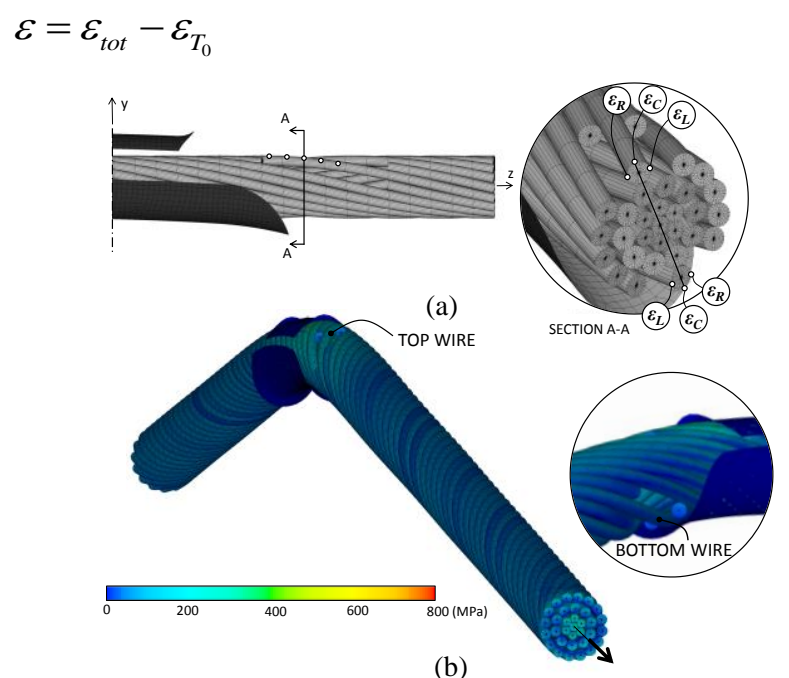

Fig. 6. (a) Schematic representation of strain gauge configuration and (b) Von Mises stress distribution (ACSR Drake at maximum deflection for $Y_{b}=$ $\left.0.90 \mathrm{~mm}\left(\beta_{0}+\Delta \beta\right)\right)$

Fig. 7(a) and (b) compare the experimental and numerical strains calculated during Load steps 4 and 5 with $T=25 \%$ RTS, before and after clamping. The evaluations are presented along the longitudinal $z$ direction, relative to $\mathrm{L}_{\mathrm{LPC}}$ established in [11]. The charts include a $20 \mathrm{~mm}$ length inward the clamps for the numerical evaluations. Fig. 7(c) and (d) compare the dynamic strain amplitudes $\left(\varepsilon_{a}\right)$ resulting from deflection amplitude variations between $Y_{b}=0.3$ and $0.9 \mathrm{~mm}$. The $\varepsilon_{a}$ values are calculated with (4) from the strain evaluation obtained during Load steps 9 and 10:

$\varepsilon_{a}=\left(\varepsilon_{\max }-\varepsilon_{\min }\right) / 2$

Results in Fig. 7(a) and (b) show good experimentalnumerical correlations for the static strains. On the top wire, the model overestimates the $\varepsilon_{\mathrm{C}}$ strains, while underestimating them at the bottom position. Although the numerical curves for the bottom wire appear to shift longitudinally by almost 50 $\mathrm{mm}$, the trends are similar. For the $\varepsilon_{\mathrm{L}}$ and $\varepsilon_{\mathrm{R}}$ strains, the model also provides predictions close to the experimental values. It should also be noted for both numerical and experimental data that the clamping does not really affect the static strains evaluated at the selected positions. Obviously, the clamp effect should be more significant at the wire-clamp contacts.

When considering the dynamic strain amplitudes $\varepsilon_{\mathrm{a}}$, Fig. 7(c) and (d) show that the model also compares very well with the experimental values. The numerical curves demonstrate some abrupt changes at the top when $Y_{b}=0.3$ $\mathrm{mm}$, while the experimental data seem to be smoother. This apparent discrepancy may originate from variations in contact 
point positions between the model and the real strand; the simulation cannot strictly reproduce the tested specimens with their local shape fluctuations, but instead, assumes theoretical ideal configurations. In other words, the real and modeled contact points displacement distribution are globally similar, but are locally different [11].

In reality, because of the complex stranding configuration and the intrinsic variability of the inter-wire contact conditions, the experimental strain scatter at the wire scale can be very significant. According to Claren and Diana [16], wire strain variations as high as $\pm 30 \%$ can be observed on adjacent wires. Ouaki et al. [17] also reported similar variations from measurements conducted on ACSR Bersfort specimens.
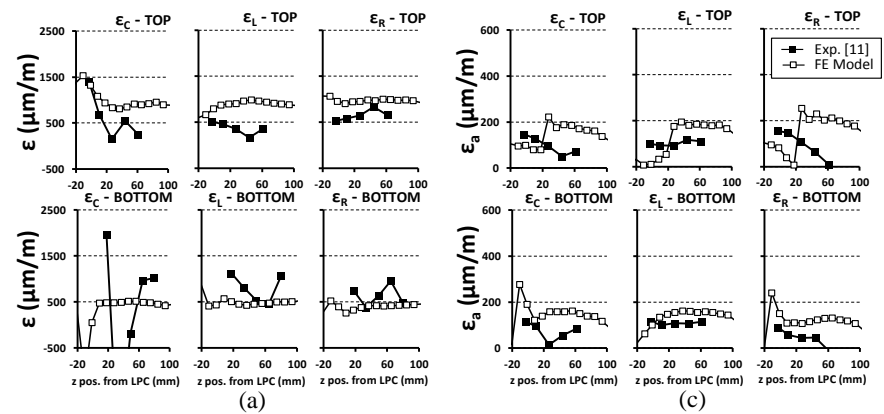

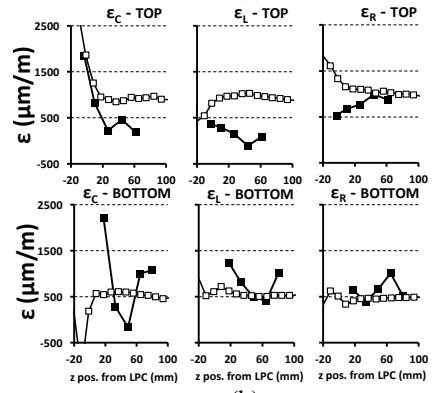

(b)

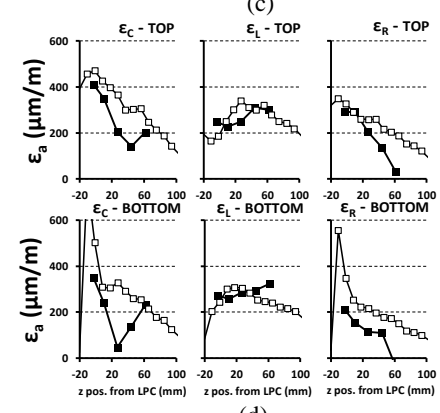

(d)
Fig. 7. ACSR Drake static strain at $\mathrm{T}=25 \%$ RTS (a) before and (b) after clamping and dynamic strain amplitude at (c) $\mathrm{Y}_{\mathrm{b}}=0.3$ and (d) $\mathrm{Y}_{\mathrm{b}}=0.9 \mathrm{~mm}$

\section{B. ACSR Bersfort case study}

The ACSR Bersfort study is conducted with the previous approach (Drake case). Therefore, Fig. 8(a) and (b) compare the experimental-numerical static strains obtained with $\mathrm{T}=$ $25 \%$ of RTS prior to and after clamping, while Fig. 8(c) and (d) present the strain amplitudes evaluated when $Y_{b}=0.32$ $\mathrm{mm}$ and $0.76 \mathrm{~mm}$.
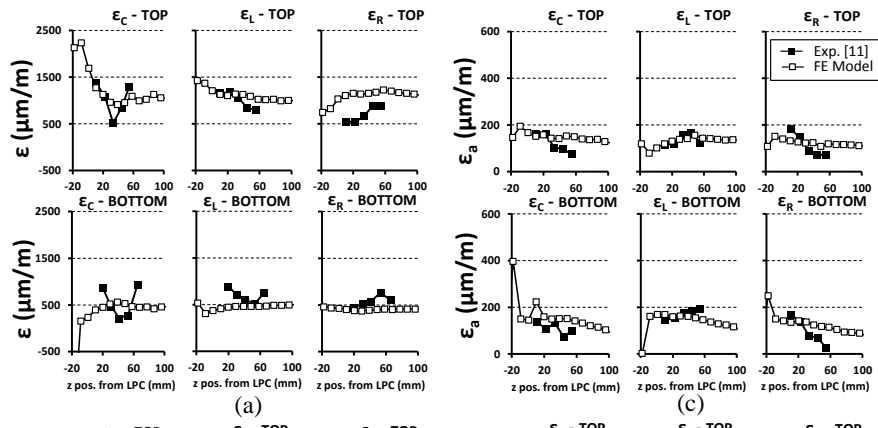

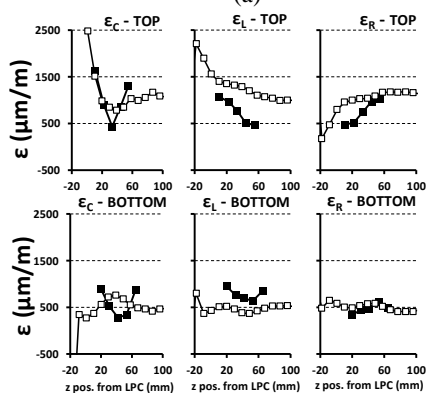

(b)

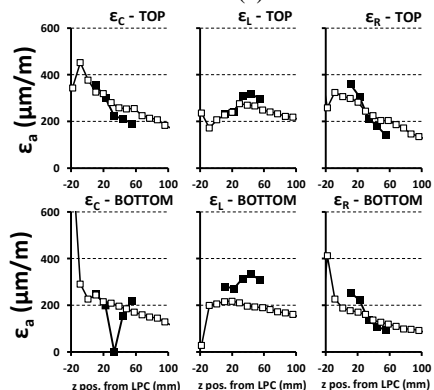

(d)
Fig. 8. ACSR Bersfort static strain at $\mathrm{T}=25 \%$ RTS (a) before and (b) after clamping and dynamic strain amplitude at (c) $\mathrm{Y}_{\mathrm{b}}=0.32$ and (d) $\mathrm{Y}_{\mathrm{b}}=0.76 \mathrm{~mm}$

Compared to the ACSR Drake case, the static strains presentation of Fig. 8(a) and (b) reveals a better match between the evaluation approaches. The same conclusions can be drawn from the results shown in Fig. 8(c) and (d), where the dynamic strain amplitude estimates present a similar agreement. It should be noted that the null experimental $\varepsilon_{C}$ strain amplitude on the bottom wire at $Y_{b}=0.76 \mathrm{~mm}$ (Fig. 8d) results from a strain gage malfunction, as reported in [11].

The comparison presented in Fig. 7 and Fig. 8 demonstrates the precision of the proposed conductor-clamp modeling approach; the model provides a reliable description of the wire internal efforts for both static and dynamic load conditions. Considering the experimental-numerical correlation levels achieved, which are well within the inherent scattering of the problem ([16][17]), the proposed model provides a very realistic representation of the conductor solicitation under wind-induced vibrations.

\section{MODEL RESPONSE ANALYSIS}

This section exploits the conductor-clamp model response to describe the internal wire stress conditions in the vicinity of suspension clamps.

\section{A. Distribution of interlayer contact interactions}

The wire interactions analysis provides meaningful information on the conductor solicitation levels. Thus, the following analyses examine local contact conditions for both ACSR modeled. Adopting a display similar to [3], [12], [18], [19], contact point statuses are mapped following four state conditions: sticking, sliding, slipping (or partial relative displacement) and no contact. As established in [12], the sliding condition refers to bulk displacements of the contacting bodies, whereas the slipping state describes slight position changes appearing only over a portion of a considered contact area. The procedure differentiates these conditions 
based on the calculated normal $(\mathrm{P})$ and tangential $(\mathrm{Q})$ interwire contact forces. In reality, since the modeling approach can only detect the sticking $(|\mathrm{Q}| \leq \mu \mathrm{P})$, sliding $(|\mathrm{Q}|>\mu \mathrm{P})$ and no contact $(\mathrm{P}=0)$ conditions, the following description associates the numerical slipping conditions with contact points experiencing a change from sticking to sliding conditions during the bending load cycles induced with $\pm \Delta \beta$.

Fig. 9 reproduces the experimental interlayer contact maps published by Zhou et al. [21] for an ACSR Drake submitted to $\mathrm{Y}_{\mathrm{b}}=0.82 \mathrm{~mm}$. The evaluations are presented along the longitudinal $z$ direction, relative to $L_{P}$.

Fig. 10 present the model contact status predictions for the same ACSR Drake conductor submitted to deflection amplitudes $Y_{b}$ of $0.3 \mathrm{~mm}$ and $0.9 \mathrm{~mm}$. The figure display the interlayer contact points and the conductor-clamp contact lines. The reference position of the keeper edge (KE) and LPC defined in [13] (see Fig. 2) are also identified in the graphs.

Fig. 10(c) indicates that the KE positions given by the FE model perfectly match the experimental one. On the other hand, the predicted LPC are offset by close to $10 \mathrm{~mm}$ inward the suspension clamp from the reference position.

The KE and LPC numerical positions are identified based on the last sticking positions on layer 3. There are many possible reasons for the observed differences. The first may be the effect of plastic deformations, for which the model does not account. These deformations adapt the conductor surface to the clamp shape, and consequently, tend to extend the contact area. The deviation could also be caused by some differences between the idealized numerical clamp profile and the real shape. Moreover, Ref. [11] indicates that LPC were measured with a thin steel strip inserted between the conductor and the clamp. In reality, the strip thickness caused an inevitable overestimation of the LPC positions. Nevertheless, despite the variations in LPC locations, the predicted contact statuses are representative of the experimental observations published by Zhou et al. [18]. The authors reported some fretting traces between the KE and LPC positions. These fretting spots could be associated with slipping movements.
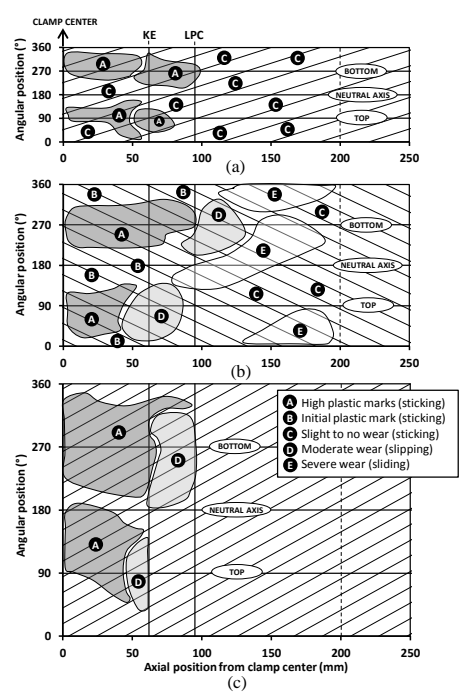

Fig. 9 - Schematization of ACSR Drake contact status mapping at $Y_{b}=0.82$ $\mathrm{mm}$, reproduced from [18], for inter-wire contacts between (a) layers 1 and 2, (b) layers 2 and 3, and (c) between layer 3 and the clamp surface
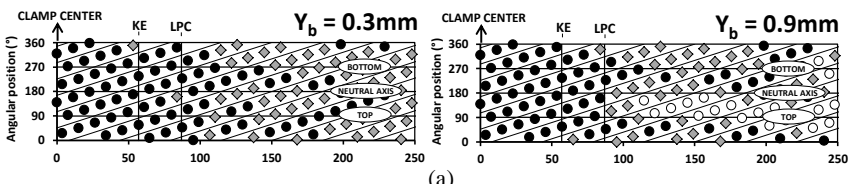
(a)
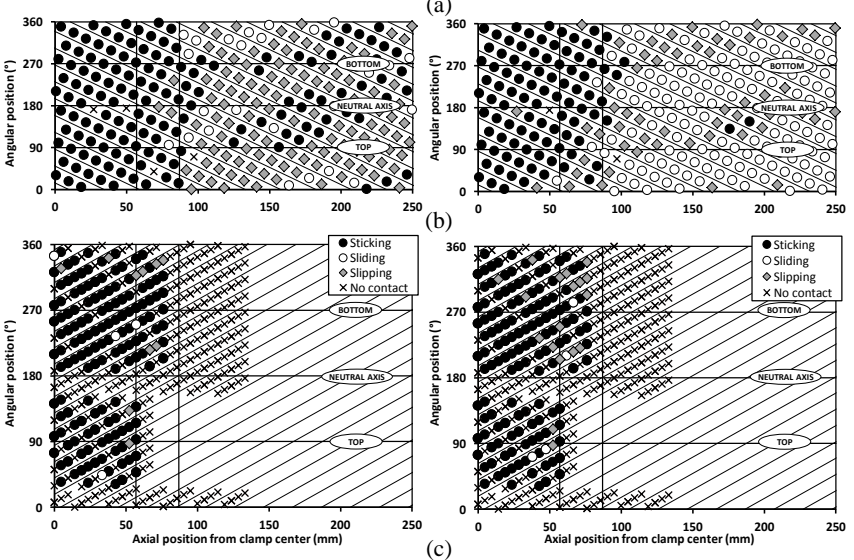

Fig. 10. ACSR Drake contact status mapping at $Y_{b}=0.3 \mathrm{~mm}$ and $0.9 \mathrm{~mm}$ for inter-wire contacts between (a) layers 1 and 2, (b) layers 2 and 3, and (c) between layer 3 and the clamp surface

A comparison between the $Y_{b}=0.3 \mathrm{~mm}$ and $Y_{b}=0.9 \mathrm{~mm}$ cases (Figs. 10) shows a global extension of the contact slipping zones with a $Y_{b}$ increase. This observation should be considered as indicative of more damaging conditions resulting from $Y_{b}$ augmentations.

When considering the layer 2-3 interface, the graphs in Fig. 10(b) indicate that a majority of the contact points are under a slipping condition when $Y_{b}=0.3 \mathrm{~mm}$, while they are in a sliding state with $Y_{b}=0.9 \mathrm{~mm}$. On the other hand, Fig. 10(a) show similar contact conditions for both deflection amplitudes between layer 2-1, although a few contact points start sliding with $Y_{b}=0.9 \mathrm{~mm}$. This tends to indicate that increasing $Y_{b}$ should cause more fretting damage to the inner layer contact interfaces. This should in turn ultimately result in higher probabilities of inner wire failure. This deduction is in line with general observations published respecting the conductor fatigue phenomenon [1].

Fig. 11 also maps the contact statuses established for the ACSR Bersfort case when $Y_{b}=0.32 \mathrm{~mm}$ and $0.76 \mathrm{~mm}$. 

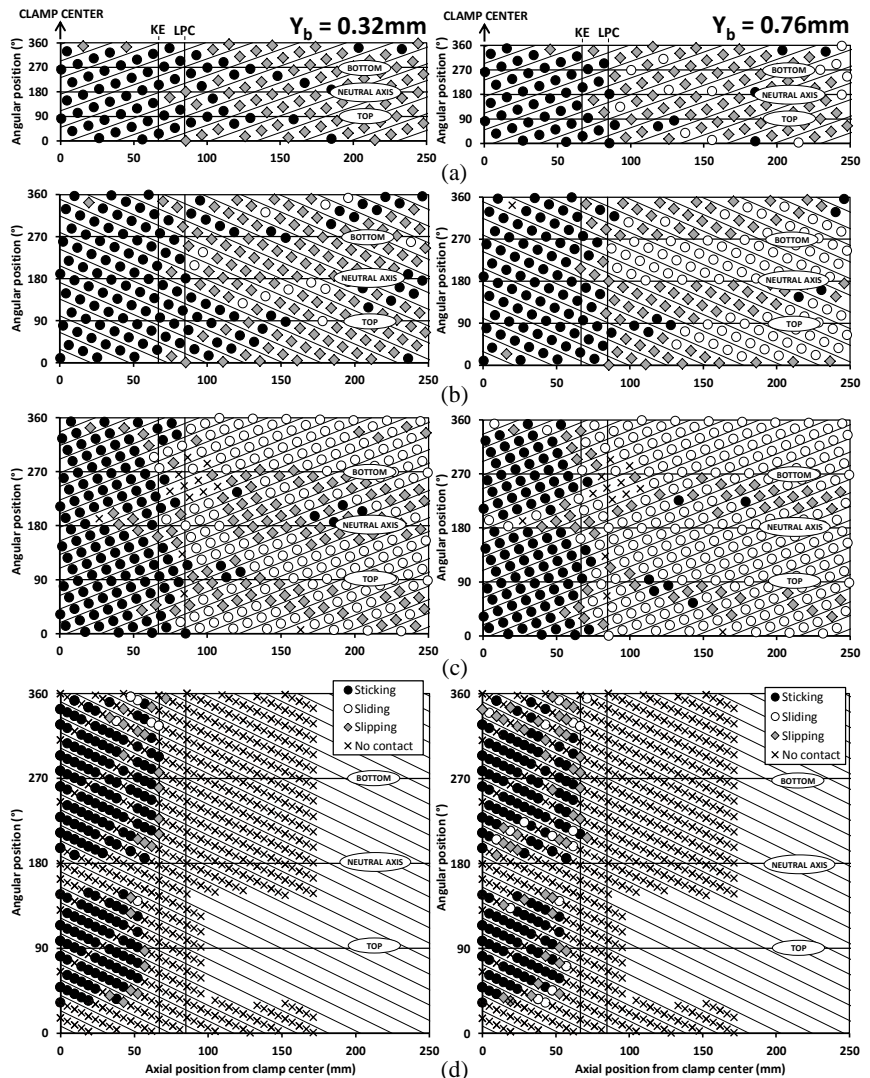

Fig. 11 ACSR Bersfort contact status mapping at $\mathrm{Y}_{\mathrm{b}}=0.32 \mathrm{~mm}$ and 0.76 $\mathrm{mm}$ for inter-wire contacts between (a) layers 1 and 2 (b) layers 2 and 3, (c) layers 3 and 4 , and (d) between layer 4 and the clamp surface

When considering the KE and LPC locations, Fig. 11(d) display responses similar to those presented in Figs. 10(c). In reality, the predicted $\mathrm{KE}$ determined for a given profile radius $R_{K, I}$ (Fig. 2) does not correspond to the reference position; the KE position given in [13] for the ACSR Bersfort test refers to the end of the keeper instead of the last contact point. In other words, the KE position reported in [13] does not account for the profile radius. Moreover, compared to the results of the ACSR Drake, more contacts at the Bersfort conductor-clamp interface (Fig. 11(d)) demonstrate slipping/sliding conditions. This situation is more significant when $Y_{b}=0.9 \mathrm{~mm}$. Since the same clamping torque is applied to both conductors, with the additional wire layer of the Bersfort conductor, the force is distributed on more wires, and therefore generates a lower clamping pressure. The frictional forces are consequently also lower. As a result, fewer contact points can sustain sticking conditions.

Finally, when considering the interlayer interfaces, as earlier, with the Drake conductor, as $Y_{b}$ increases, the contact points move from a sticking status to slipping and to sliding.

The results presented in Fig. 10 and Fig. 11 show that the model provides valuable descriptions of the contact conditions prevailing in the vicinity of the clamped region. This information is required to identify the conductor regions prone to fretting damage. In addition to the conductor geometry, these zones mainly depend on the clamp shape and the nature of the wind-induced loads. These loads are herein represented by $Y_{b}$.

\section{B. Wire Stress Distribution}

The proposed modeling approach also provides a direct evaluation of the efforts induced in the conductor wires. Thus, this section analyses the stress distributions established in the wires of the two ACSR studied. Since analyzing the wire stresses in terms of tension $\left(\sigma_{t}\right)$ and bending $\left(\sigma_{b}\right)$ stresses is more meaningful, the directional components $C, L$ and $R$ introduced in section III are rearranged with eqs. (5) and (6) below [11] as follows:

$\sigma_{t}=\left(\sigma_{L}+\sigma_{R}\right) / 2$

$\sigma_{b}=\sigma_{C}-\sigma_{t}$

Fig. 12 and Fig. 13 present the alternate part of the tension $\left(\sigma_{a, t}\right)$ and bending $\left(\sigma_{a, t}\right)$ stresses along with their combination $\left(\sigma_{a, t+b}=\sigma_{a, t}+\sigma_{a, b}\right)$ calculated for the ACSR Drake layers 2 and 3 , respectively. The graphs display the stress distributions for the complete layers (over $360 \mathrm{deg}$.) and along the longitudinal $\mathrm{z}$ direction, relative to $\mathrm{L}_{\mathrm{LPC}}$. They also include a $50 \mathrm{~mm}$ evaluation length inward the clamps. Fig. 14 and 15 adopt the same stress representation for the ACSR Bersfort layers 3 and 4 .
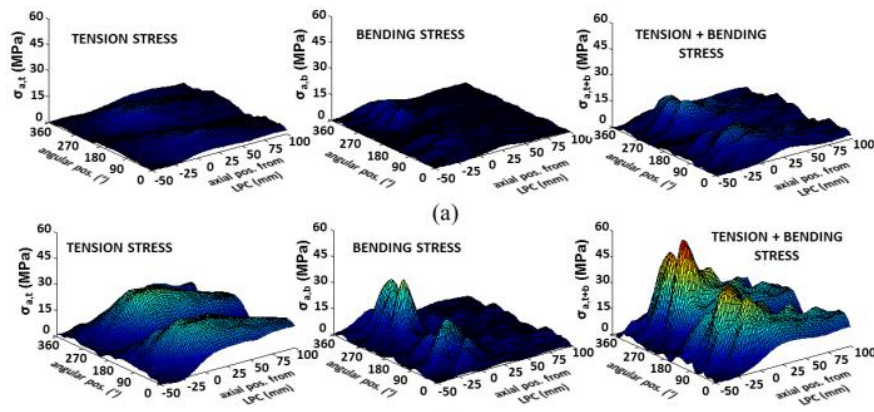

(a)
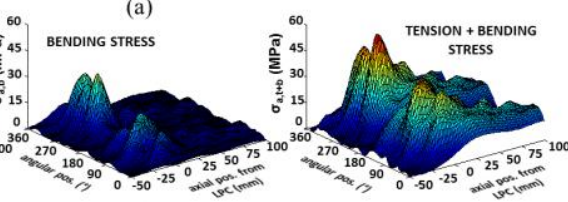

(b)

Fig. 12 Stress amplitude distributions $\sigma_{\mathrm{a}, \mathrm{t}}$ (left charts), $\sigma_{\mathrm{a}, \mathrm{b}}$ (middle charts) and $\sigma_{a, t+b}$ (right charts) for ACSR Drake wires of layer 2 for (a) $Y_{b}=0.30 \mathrm{~mm}$ and (b) $\mathrm{Y}_{\mathrm{b}}=0.90 \mathrm{~mm}$
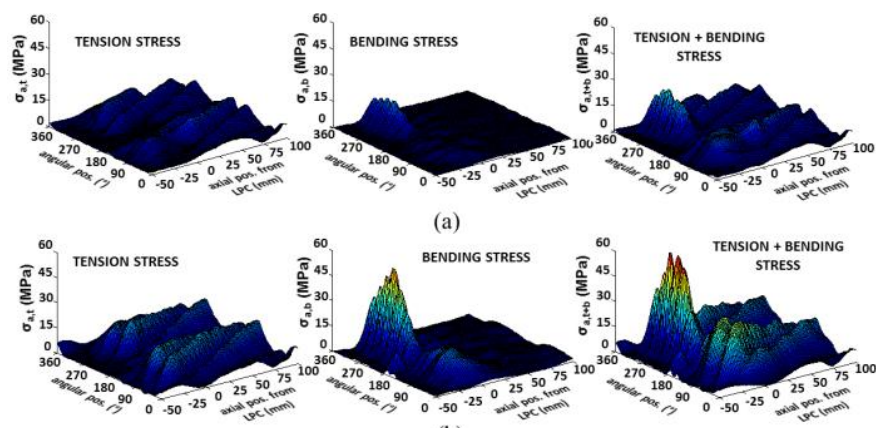

(b)

Fig. 13 Stress amplitude distributions $\sigma_{\mathrm{a}, \mathrm{t}}$ (left charts), $\sigma_{\mathrm{a}, \mathrm{b}}$ (middle charts) and $\sigma_{a, t+b}$ (right charts)) for ACSR Drake wires of layer 3 for (a) $Y_{b}=0.30 \mathrm{~mm}$ and (b) $\mathrm{Y}_{\mathrm{b}}=0.90 \mathrm{~mm}$

A rapid inspection of these figures reveals that $Y_{b}$ augmentations generate significant stress amplitude increases. Moreover, in agreement with the experimental failure observations published in [20], Figs. 12 and 13(a) indicate that the most solicited wires show up among the wires of the external layer close to the conductor-clamp contact region (270 deg. bottom position). More interestingly, at a high deflection amplitude $\left(Y_{b}=0.9 \mathrm{~mm}\right)$, the ACSR Drake inner 
layer 2 (Fig. 12 (b)) withstands $\sigma_{a, t+b}$ stress levels equivalent to those of the external layer presented in Fig. 13 (b). This condition suggests equivalent probabilities of wire failure in both layers. Moreover, for both of them, the global evaluation offered with $\sigma_{a, t+b}$ appears to be dominated by the bending component $\sigma_{a, b}$. On the other hand, the lower amplitude of $Y_{b}$ evaluated in Figs. 14 and 15 (b) $(=0.76 \mathrm{~mm})$ is apparently not high enough to get the stress in layer 3 to the level imposed on layer 4. However, the dominating influence of the bending contribution remains clear for both tested $Y_{b}$.
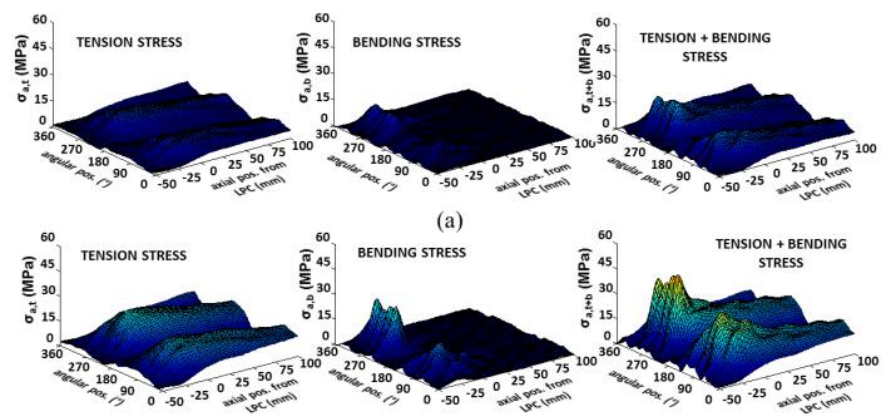

(a)

(b)

Fig. 14 Stress amplitude distributions $\sigma_{a, t}$ (left charts), $\sigma_{a, b}$ (middle charts) and $\sigma_{a, t+b}$ (right charts) for ACSR Bersfort wires of layer 3 for (a) $Y_{b}=0.32$ $\mathrm{mm}$ and (b) $\mathrm{Y}_{\mathrm{b}}=0.76 \mathrm{~mm}$
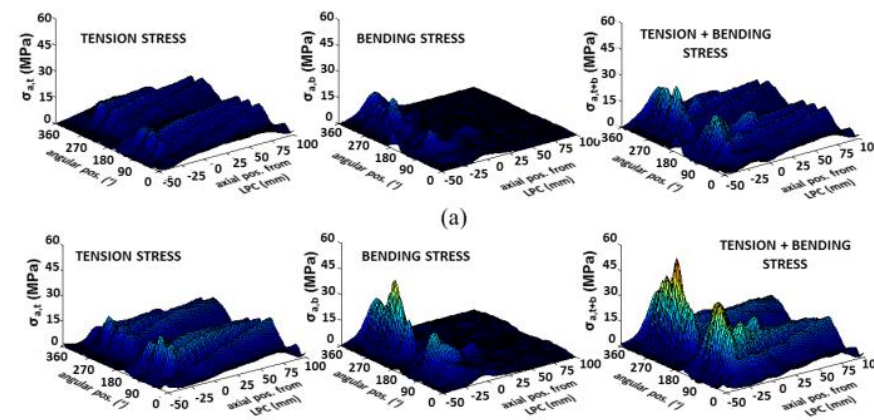

(a)
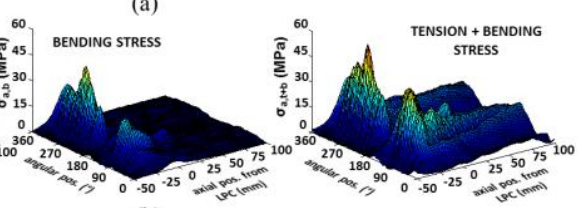

(b)

Fig. 15 Stress amplitude distributions $\sigma_{a, t}$ (left charts), $\sigma_{a, b}$ (middle charts) and $\sigma_{a, t+b}$ (right charts) for ACSR Bersfort wires of layer 4 for (a) $Y_{b}=0.32$ $\mathrm{mm}$ and (b) $\mathrm{Y}_{\mathrm{b}}=0.76 \mathrm{~mm}$

Levesque et al.'s experimental studies [11] reported that at the clamp exit, near LPC, the wires mostly sustain a tension stress $\left(\sigma_{a, t}\right)$, while the bending stress $\left(\sigma_{a, b}\right)$ remains practically negligible. The stress distributions presented in Fig. 12 to Fig. 15 agree with this observation. However, the present study indicates that between KE and LPC, the stresses are no longer driven by the alternating tension, but by an alternating bending stress $\left(\sigma_{a, b}\right)$ with an amplitude considerably higher than $\sigma_{a, t}$. This phenomenon is more significant at the bottom ( $270 \mathrm{deg}$.), but is also visible at the top $(90 \mathrm{deg}$.). Because of experimental limitations, the approach exploited by Lévesque and his coauthors could not capture this important aspect.

Experimental evidence available in the literature corroborates the above observation. For example, the FE model established maximum values of $23.2 \mathrm{MPa}, 43.4 \mathrm{MPa}$ and $56.6 \mathrm{MPa}$ for $\sigma_{a, t}, \sigma_{a, b}$ and $\sigma_{a, t+b}$ in the outer layer of the ACSR Bersfort submitted to $Y_{b}=0.76 \mathrm{~mm}$ (Fig. 15 (b)). Fatigue tests conducted by Lévesque [20] on the same conductor at a similar deflection amplitude $\left(Y_{b}=0.75 \mathrm{~mm}\right)$ and setup lead to wire failures between 1 and 2 Mcycles.
These fatigue life measurements are close to the 2-3 Mcycles obtained by Lanteigne [21] during fretting fatigue tests carried out on single wires submitted to bending loads with $\sigma_{a, b}$ between 45 and $55 \mathrm{MPa}$. For comparison purposes, fretting tests realized by Zhou et al. [22] on wires submitted to tension loads $\left(\sigma_{a, t}\right)$ conclude that below $\sigma_{a, t}=20 \mathrm{MPa}$, fretting effects are negligible. This $\sigma_{a, t}$ threshold value is very close to the tension values measured in Ref. [11], as well as to the numerical results obtained in the present study. On the other hand, the bending stresses considered in [21] correspond to the $\sigma_{a, b}$ value established with the present FE model. It therefore appears reasonable to conjecture that the combined value $\sigma_{a, t+b}=56.6 \mathrm{MPa}$ describes the stress state that leads to wire failures in [20].

As a complement to the conclusion drawn in Ref. [11], it appears that the alternating bending wire stress $\sigma_{b, t}$ is highly influential between KE and LPC, and must be included in evaluations of wire stresses induced by wind effects close to suspension clamps. By considering both stress components, the combined $\sigma_{a, t+b}$ stress evaluation provides sufficient information.

\section{CONCLUSION}

This paper presented a FE modeling approach for the analysis of conductor-clamp systems submitted to cyclic bending loads. Based on a 3D discretization of the conductor made of beam elements associated with a line-to-line contact algorithm, the proposed model takes into account all inter-wire frictional contacts. The suspension clamp body is integrated through a surface representation, where the clamping forces are incorporated via a line-to-surface contact method.

Comparisons with published strain measurements conducted on two conductor-clamp systems highlight the precision of the proposed FE strategy; the developed model provides a wire scale description of the conductor efforts caused by static and dynamic loadings.

Analyses of the model predictions also demonstrate the capacity of the approach to provide reliable descriptions of the contact point conditions in force at both interlayer and conductor-clamp interfaces. This information is crucial for identifying regions prone to fretting damage.

Finally, an analysis of stress distributions revealed that conductor wires mainly sustain tension loads near the clamp exit, but support larger bending stresses in-between KE and LPC positions. These dominant bending stresses must therefore be included in fatigue life assessments of overhead conductors.

Considering the precision and detailed information the proposed FE modeling strategy provides, it represents a useful design tool for suspension clamp systems.

\section{ACKNOWLEDGMENTS}

This research project was funded by the Natural Sciences and Engineering Research Council (NSERC) of Canada and the Hydro-Québec/RTE - Structure and mechanics of power transmission lines research chair at Université de Sherbrooke 


\section{REFERENCES}

[1] L. Cloutier, S. Goudreau, and A. Cardou, "Fatigue of overhead conductors," in EPRI Transmission line reference book: Wind-induced conductor motion, no. 1012317, Palo Alto, 2006, pp. 3.1-3.56.

[2] G. E. Ramey and J. S. Townsend, "Effects of clamps on fatigue of ACSR conductors," J. Energy Div. Proc. ASCE, vol. 107, no. 1, pp. 103-119, 1981.

[3] Z. R. Zhou, A. Cardou, S. Goudreau, and M. Fiset, "Fundamental investigations of electrical conductor fretting fatigue," Tribol. Int., vol. 29, no. 3, pp. 221-232, May 1996.

[4] IEEE, "Standardization of Conductor Vibration Measurements," IEEE Trans. Power Appar. Syst., vol. PAS-85, no. 1, pp. 10-22, 1966.

[5] J. C. Poffenberger and R. L. Swart, "Differential displacement and dynamic conductor strain," IEEE Trans. Power Appar. Syst., vol. PAS84 , no. 6 , pp. $508-513,1965$.

[6] CIGRE Study Committee \#22, "Endurance capability of conductors," 1988.

[7] A. Cardou, A. Leblond, and L. Cloutier, "Suspension clamp and ACSR electrical conductor contact conditions," J. Energy Eng., vol. 119, no. 1, pp. 19-31, 1993.

[8] F. Lévesque, S. Goudreau, L. Cloutier, and A. Cardou, "Finite element model of the contact between a vibrating conductor and a suspension clamp," Tribol. Int., vol. 44, no. 9, pp. 1014-1023, 2011.

[9] L. Cloutier, "Technology watch for gaps in knowledge about conductor fatigue - T083700-3355," Bromont, 2009.

[10] S. Lalonde, R. Guilbault, and F. Légeron, "Modeling multilayered wire strands, a strategy based on 3D finite element beam-to-beam contacts Part I: Model formulation and validation," Int. J. Mech. Sci., 2016.

[11] F. Levesque, S. Goudreau, A. Cardou, and L. Cloutier, "Strain Measurements on ACSR Conductors During Fatigue Tests IExperimental Method and Data," IEEE Trans. Power Deliv., vol. 25, no. 4, pp. 2825-2834, Oct. 2010.

[12] F. Levesque, S. Goudreau, S. Langlois, and F. Legeron, "Experimental
Study of Dynamic Bending Stiffness of ACSR Overhead Conductors," IEEE Trans. Power Deliv., vol. 30, no. 5, pp. 2252-2259, Oct. 2015.

[13] S. Goudreau, F. Levesque, A. Cardou, and L. Cloutier, "Strain Measurements on ACSR Conductors During Fatigue Tests III-Strains Related to Support Geometry," IEEE Trans. Power Deliv., vol. 25, no. 4, pp. 3007-3016, Oct. 2010.

[14] R. Judge, Z. Yang, S. W. Jones, and G. Beattie, "Full 3D finite element modelling of spiral strand cables," Constr. Build. Mater., vol. 35, pp. 452-459, 2012.

[15] J. E. Shigley, C. R. Mischke, and R. G. Budynas, Mechanical Engineering Design, 7th ed. 2004.

[16] R. Claren and G. Diana, "Dynamic Strain Distribution on Loaded Stranded Cables," IEEE Trans. Power Appar. Syst., vol. PAS-88, no. 11, pp. 1678-1690, Nov. 1969.

[17] B. Ouaki, S. Goudreau, A. Cardou, and M. Fiset, "Fretting fatigue analysis of aluminium conductor wires near the suspension clamp: Metallurgical and fracture mechanics analysis," J. Strain Anal. Eng. Des., vol. 38, no. 2, pp. 133-147, 2003.

[18] Z. R. Zhou, A. Cardou, S. Goudreau, and M. Fiset, "Fretting patterns in a conductor-clamp contact zone," Fatigue Fract. Eng. Mater. Struct., vol. 17, no. 6, pp. 661-669, 1994.

[19] Z. R. Zhou, A. Cardou, M. Fiset, and S. Goudreau, "Fretting fatigue in electrical transmission lines," Wear, vol. 173, no. 1-2, pp. 179-188, 1994.

[20] F. Lévesque, "Étude de l'applicabilité de la règle de Palmgren-Miner aux conducteurs électriques sous chargements de flexion cyclique par blocs," Universitté Laval, Québec, 2005.

[21] J. Lanteigne, Fatigue life of aluminum wires in all aluminum and ACSR conductors. Montréal: Canadian Electrical Association, 1986.

[22] Z. R. Zhou, S. Goudreau, M. Fiset, and A. Cardou, "Single wire fretting fatigue tests for electrical conductor bending fatigue evaluation," Wear, vol. 181-183, no. 2, pp. 537-543, 1995. 